\title{
Research on the Relationship between Business Cycle and Industrial Fluctuations in Northeast China Based on Complete Ensemble Empirical Mode Decomposition with Adaptive Noise
}

\author{
Yinan Zhou (D), Guofeng Gu (D), and Qiushuang Ren (iD) \\ School of Geographical Sciences, Northeast Normal University, Changchun 130024, China \\ Correspondence should be addressed to Guofeng Gu; gugf@nenu.edu.cn
}

Received 24 August 2020; Revised 1 November 2020; Accepted 23 December 2020; Published 8 January 2021

Academic Editor: Jun Yang

Copyright (c) 2021 Yinan Zhou et al. This is an open access article distributed under the Creative Commons Attribution License, which permits unrestricted use, distribution, and reproduction in any medium, provided the original work is properly cited.

\begin{abstract}
The Chinese economy has developed rapidly since the reform and opening up, but economic growth in Northeast China has declined dramatically after the 21 st century. In this context, exploring the characteristics of economic and industrial fluctuations in the northeast of China and their relationship is beneficial to alleviating economic fluctuations and promoting stable economic development from the perspective of industrial development. The relationship between economic and industrial fluctuations in the three provinces of Northeast China was reexamined from the angle of fluctuation components with the complete ensemble empirical mode decomposition with adaptive noise (CEEMDAN) algorithm. The results obtained are as follows: (1) In the three northeastern provinces of China, economic fluctuations were almost free from the influence of the primary industry, most affected by the secondary industry, and gradually influenced by the tertiary industry after the 21st century. (2) Regarding the short-term business cycle of each province, economic development was the most stable when the market and government participated in the development of the secondary industry simultaneously. (3) The midterm business cycle of Jilin Province was affected by the investment of equipment in secondary and tertiary industries, while that of Liaoning Province was affected by the investment of equipment in the secondary industry. (4) Investment in the equipment of the secondary industry and the construction of secondary and tertiary industries was the key to maintaining the stability of long-term business cycle in Heilongjiang Province, and that in the construction of secondary and tertiary industries was the key to maintaining the stability of long-term business cycles in Jilin and Liaoning Provinces.
\end{abstract}

\section{Introduction}

Economy has maintained steady and rapid growth in China since the reform and opening up but experienced severe economic downturns in the three northeastern provinces of China in the 1990s and 2010s. The growth rate of gross domestic product (GDP) in the three northeastern provinces of China is much less than the national average, and obvious problems exist in various indicators of economic operation. According to the historical experience of all countries around the world in economic development, an economic system always shows fluctuations regardless of system type or development stage, which is specifically manifested in the fluctuation level of economic activities, namely, business cycle. As two basic forms of economic system evolution, economic and industrial fluctuations are inseparable from each other. In this context, studying the relationship between economic and industrial fluctuations in the three northeastern provinces of China is of important practical significance to make policy recommendations to alleviate the problems of Northeast China from the perspective of industry, thereby reducing economic fluctuations and maintaining the sustainable development of economy in the northeast of China.

The academic circles have three different viewpoints about the relationship between economic fluctuations and industrial structure changes. The first point of view comes from the community of mainstream economics, believing that economic fluctuations determine industrial fluctuations and industrial structure changes [1]. Kuznets analyzed the 
impact of the economic growth rate on the range of changes in the production structure and concluded that structural change is an important fact in the fluctuation of modern economic growth [2]. Berman and Pfleeger studied the industries where demand and employment are sensitive to economic fluctuations, which can predict the industries changing in sync with business cycle in the future and identify industrial fluctuations [3]. Lin et al. believed that the reason for different industrial structures in different countries at different stages of business cycle is that the upgrading of industrial structure is up to the structure change of the factor endowment of economy, which is mainly affected by the stage of economic growth. Fundamentally speaking, economic growth fluctuations cause the change of industrial structure $[4,5]$. Ma conducted a theoretical and empirical study on the relationship between economic fluctuations and industrial structure changes and found that a variety of industries are sensitive to business cycles to varying degrees, with the secondary industry showing the highest sensitivity [6-9].

The second point of view comes from development economics with structuralism as the basic idea, believing that the change of industrial structure brings about economic fluctuations. Li held that macroeconomic fluctuations are mainly caused by the fluctuations of primary and secondary industries [10]. Chen maintained that economic fluctuations have a high degree of synergy with the fluctuations of the three industries and subindustry sectors in China. Tertiary, secondary, and primary industries, respectively, have an impact on business cycle, whose influence degree decreases in order [11]. Sonobe and Otsuka demonstrated the important relationship between industrial structure changes and economic growth fluctuations in Japan before the Second World War [12]. Peneder examined the connection between industrial structure changes and economic fluctuations using the data from Organization for Economic Cooperation and Development (OECD) countries and observed that industrial structure explained $30 \%$ of the reduction of economic volatility [13]. Fan et al. came to the conclusion that structural change can explain $17 \%$ of the fluctuation of economic growth in China, which was in line with the research conclusions of Li et al. [14-16]. In addition, Eggers and Ioannides pointed out that the structural shift from manufacturing to the service industry effectively reduced economic volatility in the United States (US) [17]. Burns demonstrated the impact of industrial structure changes on the fluctuations of business cycle in the US [18]. Gordon emphasized the role of economic structural changes in the stabilization of business cycle in his collection of essays on the business cycle of the US [19]. Moreover, some researchers analyzed the relationship between industrial structure changes and economic fluctuations in China and believed that industrial structure changes have a "smoothing effect" on macroeconomic fluctuations [20-23]. Ding and Zhang reached similar conclusions by analyzing the association between industrial structure changes and economic fluctuations in Japan [24].

The third view believes that economic fluctuations and industrial structure changes influence each other [25-29].
Zhang and Liu found that the fluctuations of industrial output growth are an important component of business cycle fluctuations which have a feedback effect on industrial output fluctuations [30]. Li et al. demonstrated the causal and dynamic relationships between industrial and economic fluctuations in Taiwan Province [31, 32]. Jiang and Jiao investigated the influence of industrial structure evolution on economic fluctuations in Shanxi Province and concluded that three industrial and economic fluctuations in Shanxi Province have Granger causality after the reform and opening up [33]. Jiang, Zhang, and Jiang analyzed the correlation between the fluctuations of the producer service industry and the economy in China and reached the conclusion that developing the producer service industry can stabilize economic fluctuations which however are not conducive to developing the producer service industry [34].

Conclusions about the relationship between economic and industrial fluctuations are inconsistent due to different research areas and methods. From the perspective of the frequency domain, filtering algorithms like collaborative filtering (CF) and Hodrick-Prescott (HP) filtering were mostly used in the past and require selecting a basis function at first, which is highly subjective. Different basis functions will produce different research results. By contrast, the complete ensemble empirical mode decomposition with adaptive noise (CEEMDAN) algorithm has no need to select a basis function and require the stability and linearity of data without losing data information, which is beneficial to obtain more objective and accurate research results. In order to determine the relationship between economic and industrial fluctuations in the northeast of China, the timeseries data of economic and industrial fluctuations in the three northeastern provinces of China from 1978 to 2018 were used, and the EMD algorithm was selected to analyze the following main issues: (1) What are the characteristics of economic and industrial fluctuations in the three northeast provinces of China since the reform and opening up? (2) What is their relationship? (3) What are the similarities and differences between economic and industrial fluctuations in the three provinces of Northeast China?

The remainder of this paper was organized as follows. Section 2 examined economic and industrial fluctuations in the three northeastern provinces of China since the reform and opening up, made an introduction of data sources, and expounded the basic ideas and steps of the CEEMDAN algorithm. Section 3 decomposed the sequences of economic and industrial fluctuations in the three northeastern provinces of China to obtain components and analyzed the characteristics of each fluctuation component. Section 4 examined the relationship between the components of economic and industrial fluctuations in each province. Section 5 discussed the research methods and content of this paper. Section 6 made a summary of research conclusions.

\section{Materials and Methods}

2.1. Materials. In this paper, the data from 1978 to 2018 were used to conduct empirical analysis. The data from 1978 to 1992 were selected from the China Compendium of 
Statistics 1949-2008, and those between 1993 and 2018 were sourced from provincial-level statistics on the website of the National Bureau of Statistics. Provincial GDP data (previous year $=100$ ) were processed to obtain the real GDP growth rate of each province from 1978 to 2018 to measure the economic fluctuations of each province. The fluctuation cycles of each industry in each province were measured by using the value-added data (previous year $=100$ ) of primary, secondary, and tertiary industries in each province from 1978 to 2018. Figure 1 shows a line chart of the GDP growth rate of each province and the growth rates of primary, secondary, and tertiary industries.

Fluctuation curves of the GDP growth rates of Heilongjiang, Jilin, and Liaoning Provinces are shown in Figures 1(a)-1(c) which demonstrate that the GDP growth rates of the three provinces were slightly different in different periods but presented similar overall trends after the reform and opening up. Before the 21st century, they showed a trend of uneven growth. After the 21st century, economy showed a steady growth trend until approximately 2010 due to the decrease in the fluctuations in GDP growth rates. Then, GDP growth rates began to decline, which produced the so-called "New Northeast Phenomenon." From the perspective of industrial fluctuations, first of all, the natural environment played a decisive in the development of the primary industry which therefore experienced the largest fluctuations among the three industries of each province. Second, the fluctuation trends of secondary and tertiary industries were similar to that of the GDP growth rate due to the planned economy, and the fluctuation range was wide during the period between the reform and opening up and the 1990s when government decisions were of decisive importance for economic development. In 1992, a socialist market economic system was established in China. With the function of self-regulation, the market played a leading part in economic development. Various industries saw stable growth and a decline in fluctuations. The main driving force for the Chinese economy at the time was the secondary industry which showed a more obvious growth trend than the tertiary industry. By 2010, the growth rates of secondary and tertiary industries declined to varying degrees, and the decline in the growth rate of the secondary industry was significantly higher than that of the tertiary industry.

From the above, it can be seen that the industrial fluctuations in the three provinces have certain similarities with the economic fluctuations in corresponding provinces, especially in secondary and tertiary industries. Cycles were further subdivided below for analysis and discussion.

2.2. Methods. The CEEMDAN algorithm is the main research method in the paper. This algorithm is a frequency domain analysis method for analyzing time-series data. It is based on the empirical mode decomposition (EMD) algorithm proposed by Huang et al.

The basic idea of the EMD is the following: time-series data are composed of many different coexisting internal mode functions (IMFs) at any time and the final complex data can be obtained by superimposing each mode function.
The algorithm is different from other frequency domain processing methods since it does not need to set any basis functions in advance. In addition, it can be applied to decompose various time-series data, and it especially has a very obvious advantage when dealing with nonstationary and nonlinear data $[35,36]$.

The steps of CEEMDAN algorithm are as follows.

Step 1. Assuming that the original time-series data is $x(t)$, let $i=1, \ldots, I$. Then decompose the time-series data using EMD algorithm which added the adaptive white noise and getting the first IMF component:

$$
\begin{aligned}
& \operatorname{imf}_{1}=\frac{1}{2}\left(\frac{1}{I} \sum_{i=1}^{I} E_{1+}\left(x(t)^{t}\right)\right)+\frac{1}{I} \sum_{i=1}^{I} E_{1-}\left(x(t)^{t}\right), \\
& i=1, \cdots, I .
\end{aligned}
$$

Step 2. Calculate the remainder by excluding the first IMF component:

$$
r_{1}(t)=x(t)-\mathrm{imf}_{1} .
$$

Step 3. Treat $r_{1}(t)$ as a new original sequence and repeat Steps 1 and 2 to obtain the remaining components $\operatorname{imf}_{2}, \cdots$, and $\operatorname{imf}_{n}$ and remaining terms $r_{n}(t)$. The condition for stopping the decomposition is that the remaining term $r_{n}(t)$ cannot be decomposed, which is the trend term res $=r_{n}(t)$.

After the above steps, the original sequence can be decomposed into $n$ IMFs and a trend term; that is,

$$
x(t)=\sum_{i=1}^{n} \operatorname{imf}_{i}+\text { res },
$$

where $\mathrm{IMF}_{i}$ is the $i$ th component obtained by decomposing original time-series data and res is the trend term.

\section{Empirical Analysis}

3.1. Business Cycle Analysis. With the help of MATLAB R2016b, the GDP growth rate data of Heilongjiang, Jilin, and Liaoning Provinces were decomposed using CEEMDAN algorithm to obtain the cycle components and trend terms of economic fluctuations in each province, as shown in Figure 2. The results of Heilongjiang, Jilin, and Liaoning Provinces are shown in the first, second, and third columns, respectively. The first to fourth lines are economic cycle components, and the fifth line is the trend term.

From the shapes of business cycles and trend terms in Figure 2, it can be intuitively seen that business cycles corresponding to the frequencies between provinces are similar. From the perspective of fluctuation amplitude, highfrequency components (IMFs 1 and 2) fluctuated violently from 1978 to the 1990s and gradually turned into smallamplitude fluctuations after the 1990s. The fluctuation amplitudes of low-frequency components (IMFs 3 and 4) were slight before the 21st century and gradually increased 


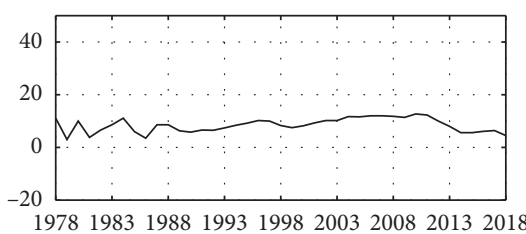

(a)

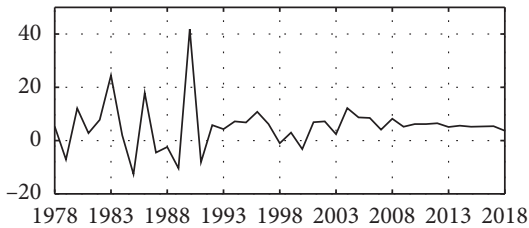

(d)

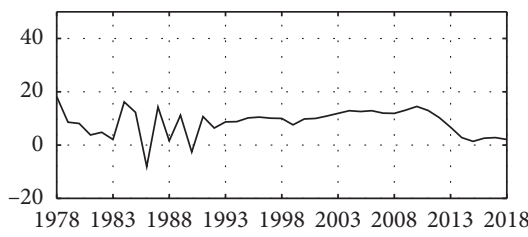

(g)

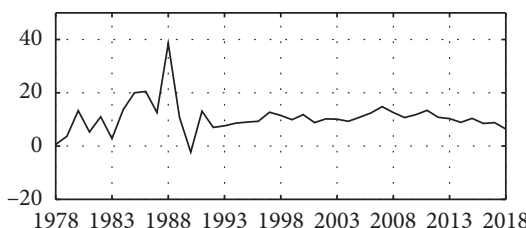

(j)

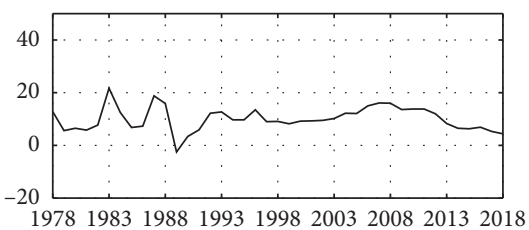

(b)

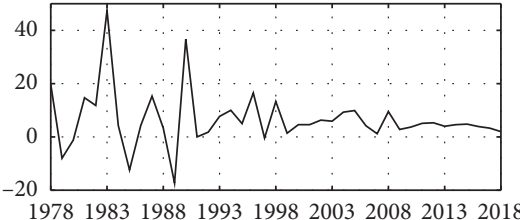

(e)

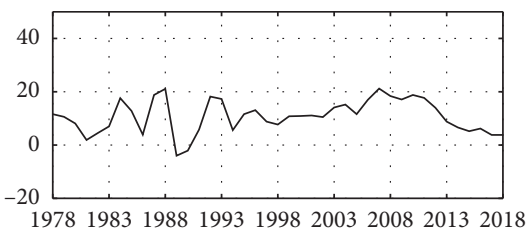

(h)

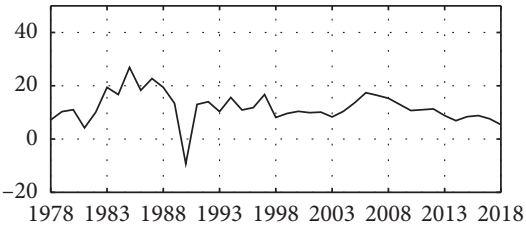

(k)

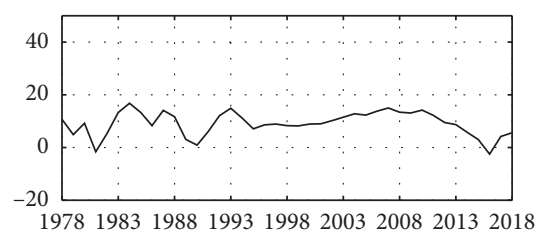

(c)

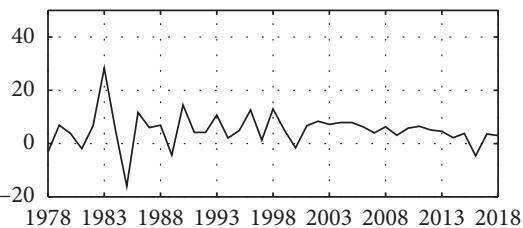

(f)

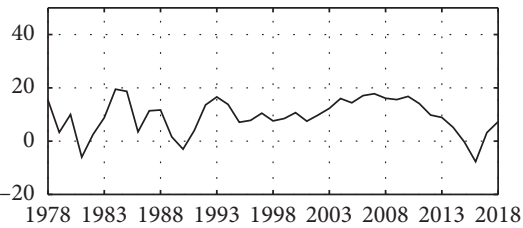

(i)

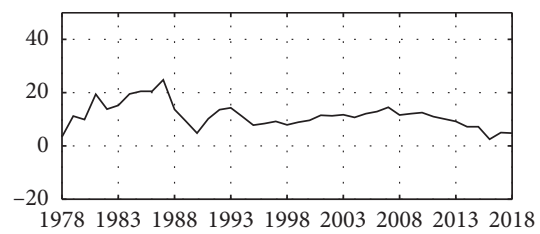

(1)

FIGURE 1: Fluctuation curves of GDP growth rate and value added of each industry in the three provinces: (a) GDP of Heilongjiang, (b) GDP of Jilin, (c) GDP of Liaoning, (d) primary industry of Heilongjiang, (e) primary industry of Jilin, (f) primary industry of Liaoning, (g) secondary industry of Heilongjiang, (h) secondary industry of Jilin, (i) secondary industry of Liaoning, (j) tertiary industry of Heilongjiang, (k) tertiary industry of Jilin, and (l) tertiary industry of Liaoning.

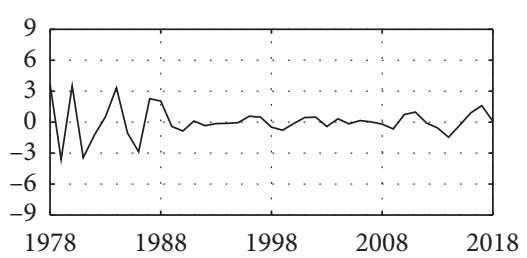

(a)

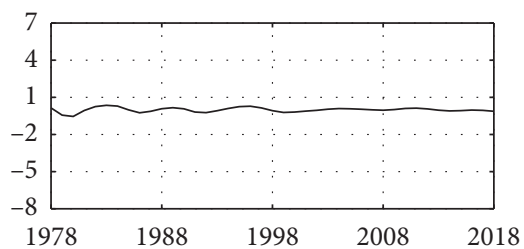

(d)

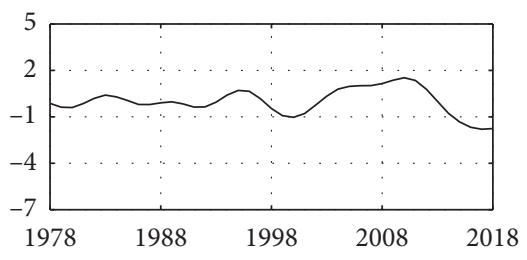

(g)

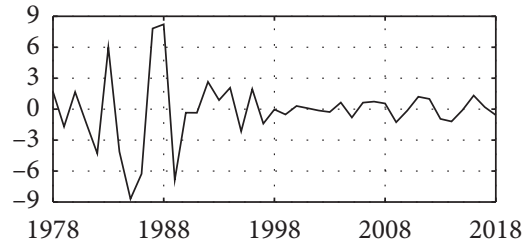

(b)

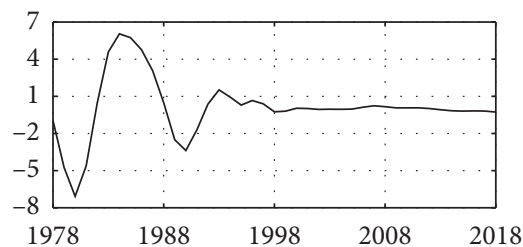

(e)

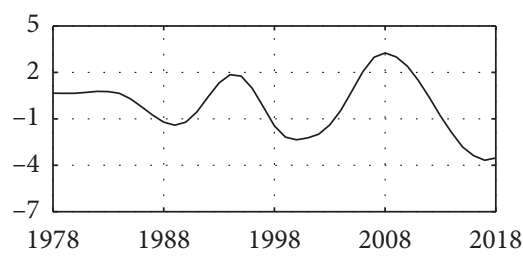

(h)

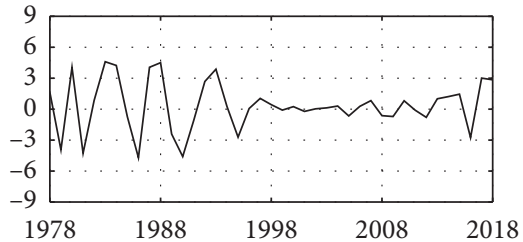

(c)

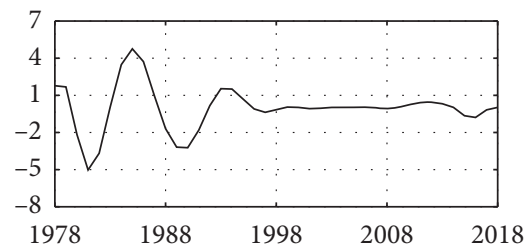

(f)

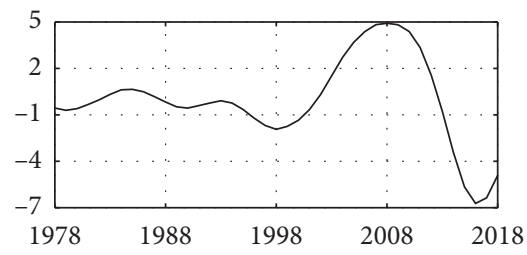

(i)

Figure 2: Continued. 


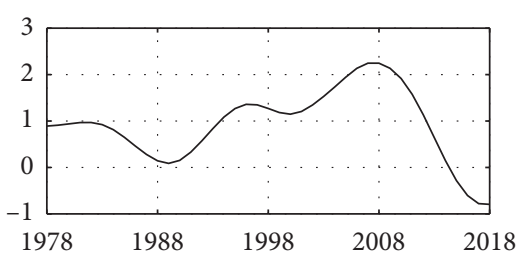

(j)

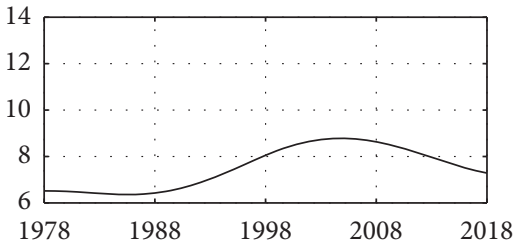

(k)

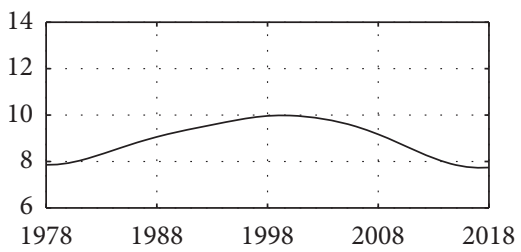

(m)

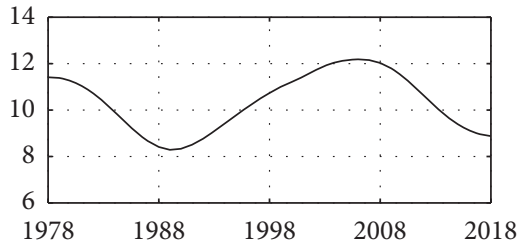

(l)

FIGURE 2: Economic fluctuation components and trend items of various provinces (a). IMF1 of Heilongiiang (b). IMF1 of Jilin (c). IMF1 of Liaoning (d). IMF2 of Heilongjiang (e). IMF2 of Jilin (f). IMF2 of Liaoning (g). IMF3 of Heilongjiang (h). IMF3 of Jilin (i). IMF3 of Liaoning (j). IMF4 of Heilongjiang (k). RES of Heilongjiang (l). RES of Jilin (m). RES of Liaoning.

over time. The trend term in each province had an "invertedU" shape and reached a peak in the early 21 st century.

In addition to the above common features that can be intuitively observed from Figure 2, business cycles have differences. To more fully understand the features of business cycle components and the trend terms of economic fluctuations, relevant characteristics are summarized in Table 1.

The frequencies of business cycles changed with time without a fixed period. Therefore, the amount of data contained in each business cycle component was divided by the number of the extreme points of corresponding components to represent the average period. According to the difference in the average cycle duration and influencing factors, business cycle can be divided into Kitchin, political economy, Juglar, Kuznets, and Kondratiev cycles. Also called the inventory or short cycle, the Kitchin cycle is a regular short-term fluctuation discovered by American economist Kitchin, whose fluctuation is related to the changes in commercial inventory and duration is approximately 40 months. The political economic cycle is caused by the promotion system cycle of China, government changes, the Five-Year Plan, and the influence of macrocontrol. Also known as the equipment investment cycle or midcycle, the Juglar cycle was found by French economists Juglar, whose fluctuation is approximately 10 years and results from the fluctuations in equipment investment. Also known as the construction cycle or the middle cycle, the Kuznets cycle is a 20 -year economic cycle caused by the cyclical changes in construction activities and discovered by American economist Kuznets. Found by Russian economist Kondratiev, the Kondratiev cycle is a long cycle of $50-60$ years that is attributed to technological progress and innovation. Different business cycle fluctuations have formed in a variety of regions because of the above five cycles and their superposition [37].
As shown in Table 1, the business cycle components of Heilongiiang Province include Kitchin, Juglar, Kuznets, and Kondratiev cycles. All cyclical components and trend terms were significantly associated with the original time-series sequence. From the perspective of the variance contribution rate, the Kitchin cycle had the greatest impact on economic fluctuations and achieved a variance contribution rate of as high as $51.95 \%$. The Juglar cycle had the smallest impact on economic fluctuations, which can be ignored. The rest of the components and trend terms had similar effects on economic fluctuation series. Business cycle components in Jilin and Liaoning Provinces were different from those in Heilongjiang Province because of excluding Kitchin and Kondratiev cycles and being replaced by the political economic cycle. In addition, they include Juglar and Kuznets cycles. Each component was significantly related to the original sequence which had the weakest relationship with trend terms. The political economic cycle had the greatest impact on the economic fluctuations of Jilin Province, while the Kuznets cycle had the greatest impact on the economic fluctuations of Liaoning Province.

3.2. Industry Cycle Analysis. The fluctuation components and trend terms of various industries were obtained by dealing with the growth rates data on the value added of primary, secondary, and tertiary industries of each province. Due to space limitations, the visual map of decomposition results was omitted here. Table 2 summarizes the statistical information of industrial fluctuation cycle components and trend terms by province.

As seen from Table 2, the fluctuations of each industry in each province include four periodic components and one trend term reflecting the development trend of industries. In addition, only a few trend terms were statistically correlated with the corresponding original sequence or had a greater 
TABLE 1: Statistical features of the business cycle components and trend terms.

\begin{tabular}{|c|c|c|c|c|c|c|c|c|}
\hline Province & Component & $\begin{array}{c}\text { Average } \\
\text { period (year) }\end{array}$ & Frequency & Type & $\begin{array}{l}\text { Person correlation } \\
\text { coefficient }\end{array}$ & Var. & $\begin{array}{c}\text { Contribution rate of } \\
\text { var. }(\%)\end{array}$ & $\begin{array}{l}\text { Impact } \\
\text { ranking }\end{array}$ \\
\hline \multirow{5}{*}{ Heilongjiang } & IMF 1 & 2.2 & High & Kitchin cycle & $0.57^{* * *}$ & 2.27 & 51.95 & 1 \\
\hline & IMF 2 & 7.0 & Medium & Juglar cycle & $0.42^{* * *}$ & 0.03 & 0.76 & 5 \\
\hline & IMF 3 & 21.0 & Low & Kuznets cycle & $0.70^{* * *}$ & 0.69 & 15.69 & 3 \\
\hline & IMF 4 & 41.0 & Low & Kondratiev cycle & $0.74^{* * *}$ & 0.59 & 13.59 & 4 \\
\hline & RES & $\infty$ & Low & & $0.60^{* * *}$ & 0.79 & 18.01 & 2 \\
\hline \multirow{4}{*}{ Jilin } & IMF 1 & 4.2 & High & $\begin{array}{c}\text { Political } \\
\text { economic cycle }\end{array}$ & $0.64^{* * *}$ & 9.90 & 48.10 & 1 \\
\hline & IMF 2 & 10.5 & Medium & Juglar cycle & $0.46^{* * *}$ & 5.91 & 28.73 & 2 \\
\hline & IMF 3 & 14.0 & Low & Kuznets cycle & $0.55^{* * *}$ & 3.23 & 15.70 & 3 \\
\hline & RES & $\infty$ & Low & & $0.33^{* *}$ & 1.54 & 7.47 & 4 \\
\hline \multirow{4}{*}{ Liaoning } & IMF 1 & 5.3 & High & $\begin{array}{c}\text { Political } \\
\text { economic cycle }\end{array}$ & $0.53^{* * *}$ & 5.83 & 33.51 & 2 \\
\hline & IMF 2 & 8.4 & Medium & Juglar cycle & $0.57^{* * *}$ & 3.23 & 18.58 & 3 \\
\hline & IMF 3 & 21.0 & Low & Kuznets cycle & $0.69^{* * *}$ & 7.74 & 44.44 & 1 \\
\hline & RES & $\infty$ & Low & & $0.36^{* *}$ & 0.61 & 3.48 & 4 \\
\hline
\end{tabular}

Note. Asterisks mean that the figure is statistically significant; ${ }^{*},{ }^{* *}$, and ${ }^{* * *}$ indicate $P<0.1, P<0.05$, and $P<0.1$, respectively.

TABLE 2: Statistical features of components and trend terms of industrial cycle.

\begin{tabular}{|c|c|c|c|c|c|c|}
\hline Province & Industry & Component & $\begin{array}{l}\text { Average period } \\
\text { (year) }\end{array}$ & Type & $\begin{array}{c}\text { Person correlation } \\
\text { coefficient }\end{array}$ & $\begin{array}{c}\text { Contribution rate of var. } \\
(\%)\end{array}$ \\
\hline \multirow{15}{*}{ Heilongjiang } & \multirow{5}{*}{$\begin{array}{l}\text { Primary } \\
\text { industry }\end{array}$} & IMF 1 & 2.1 & \multirow{3}{*}{$\begin{array}{c}\text { Kitchin cycle } \\
\text { Political economic } \\
\text { cycle } \\
\text { Juglar cycle }\end{array}$} & $0.78^{* * *}$ & 60.75 \\
\hline & & IMF 2 & 4.7 & & $0.47^{* * *}$ & 28.48 \\
\hline & & IMF 3 & 10.5 & & 0.25 & 10.00 \\
\hline & & IMF 4 & 21.0 & Kuznets cycle & 0.05 & 0.26 \\
\hline & & RES & $\infty$ & \multirow{3}{*}{$\begin{array}{c}\text { Kitchin cycle } \\
\text { Political economic } \\
\text { cycle }\end{array}$} & 0.03 & 0.51 \\
\hline & \multirow{5}{*}{$\begin{array}{l}\text { Secondary } \\
\text { industry }\end{array}$} & IMF 1 & 2.2 & & $0.67^{* * *}$ & 61.71 \\
\hline & & IMF 2 & 4.7 & & $0.46^{* * *}$ & 10.03 \\
\hline & & IMF 3 & 8.4 & Juglar cycle & $0.58^{* * *}$ & 5.53 \\
\hline & & IMF 4 & 14.0 & Kuznets cycle & $0.59^{* * *}$ & 12.44 \\
\hline & & RES & $\infty$ & & $0.54^{* * *}$ & 10.28 \\
\hline & \multirow{5}{*}{$\begin{array}{l}\text { Tertiary } \\
\text { industry }\end{array}$} & IMF 1 & 3.0 & Kitchin cycle & $0.72^{* * *}$ & 45.20 \\
\hline & & IMF 2 & 8.4 & Juglar cycle & 0.12 & 19.86 \\
\hline & & IMF 3 & 14.0 & Kuznets cycle & $0.58^{* * *}$ & 30.19 \\
\hline & & IMF 4 & 21.0 & Kuznets cycle & $0.39^{* *}$ & 4.24 \\
\hline & & RES & $\infty$ & & 0.08 & 0.52 \\
\hline \multirow{15}{*}{ Jilin } & \multirow{5}{*}{$\begin{array}{l}\text { Primary } \\
\text { industry }\end{array}$} & IMF 1 & 3.2 & Kitchin cycle & $0.73^{* * *}$ & 59.68 \\
\hline & & IMF 2 & 7.0 & Juglar cycle & $0.37^{* *}$ & 33.32 \\
\hline & & IMF 3 & 14.0 & Kuznets cycle & 0.17 & 3.16 \\
\hline & & IMF 4 & 21.0 & Kuznets cycle & 0.13 & 0.17 \\
\hline & & RES & $\infty$ & \multirow[b]{2}{*}{$\begin{array}{l}\text { Political economic } \\
\text { cycle }\end{array}$} & 0.17 & 3.67 \\
\hline & \multirow{5}{*}{$\begin{array}{l}\text { Secondary } \\
\text { industry }\end{array}$} & IMF 1 & 4.7 & & $0.77^{* * *}$ & 69.20 \\
\hline & & IMF 2 & 8.4 & Juglar cycle & $0.55^{* * *}$ & 7.96 \\
\hline & & IMF 3 & 14.0 & Kuznets cycle & $0.56^{* * *}$ & 10.96 \\
\hline & & IMF 4 & 21.0 & Kuznets cycle & $0.59^{* * *}$ & 4.92 \\
\hline & & RES & $\infty$ & & $0.38^{* *}$ & 6.97 \\
\hline & \multirow{5}{*}{$\begin{array}{l}\text { Tertiary } \\
\text { industry }\end{array}$} & IMF 1 & 3.0 & Kitchin cycle & $0.57^{* * *}$ & 29.83 \\
\hline & & IMF 2 & 10.5 & Juglar cycle & $0.55^{* * *}$ & 48.55 \\
\hline & & IMF 3 & 14.0 & Kuznets cycle & 0.26 & 13.04 \\
\hline & & IMF 4 & 21.0 & Kuznets cycle & 0.12 & 6.32 \\
\hline & & RES & $\infty$ & & 0.21 & 2.27 \\
\hline
\end{tabular}


TABLE 2: Continued.

\begin{tabular}{|c|c|c|c|c|c|c|}
\hline Province & Industry & Component & $\begin{array}{l}\text { Average period } \\
\text { (year) }\end{array}$ & Type & $\begin{array}{c}\text { Person correlation } \\
\text { coefficient }\end{array}$ & $\begin{array}{c}\text { Contribution rate of var } \\
(\%)\end{array}$ \\
\hline \multirow{15}{*}{ Liaoning } & \multirow{5}{*}{$\begin{array}{l}\text { Primary } \\
\text { industry }\end{array}$} & IMF 1 & 3.2 & \multirow{2}{*}{$\begin{array}{c}\text { Kitchin cycle } \\
\text { Political economic } \\
\text { cycle }\end{array}$} & $0.73^{* * *}$ & 66.16 \\
\hline & & IMF 2 & 5.3 & & $0.42^{* * *}$ & 27.20 \\
\hline & & IMF 3 & 10.5 & Juglar cycle & 0.23 & 2.96 \\
\hline & & IMF 4 & 21.0 & Kuznets cycle & 0.14 & 1.24 \\
\hline & & RES & $\infty$ & & 0.20 & 2.44 \\
\hline & \multirow{5}{*}{$\begin{array}{l}\text { Secondary } \\
\text { industry }\end{array}$} & IMF 1 & 3.8 & Kitchin cycle & $0.57^{* * *}$ & 38.89 \\
\hline & & IMF 2 & 8.4 & Juglar cycle & $0.56^{* * *}$ & 14.95 \\
\hline & & IMF 3 & 21.0 & Kuznets cycle & $0.67^{* * *}$ & 36.59 \\
\hline & & IMF 4 & 41.0 & Kondratiev cycle & $0.44^{* * *}$ & 9.56 \\
\hline & & RES & $\infty$ & & 0.08 & 0.01 \\
\hline & \multirow{5}{*}{$\begin{array}{l}\text { Tertiary } \\
\text { industry }\end{array}$} & IMF 1 & 2.6 & Kitchin cycle & $0.45^{* * *}$ & 21.23 \\
\hline & & IMF 2 & 7.0 & Juglar cycle & $0.63^{* * *}$ & 9.21 \\
\hline & & IMF 3 & 14.0 & Kuznets cycle & $0.68^{* * *}$ & 14.89 \\
\hline & & IMF 4 & 21.0 & Kuznets cycle & $0.60^{* * *}$ & 14.32 \\
\hline & & RES & $\infty$ & & $0.53^{* * *}$ & 40.35 \\
\hline
\end{tabular}

Note. Asterisks mean that the figure is statistically significant; ${ }^{*},{ }^{* *}$, and ${ }^{* * *}$ indicate $P<0.1, P<0.05$, and $P<0.1$, respectively.

variance contribution rate. Therefore, trend terms were not used as the main research objects. Below is a discussion on the consistency and heterogeneity of the characteristics of industrial fluctuation cycles by province.

The fluctuation components of each industry in Heilongjiang Province include Kitchin (high frequency), Juglar (midfrequency), and Kuznets cycles (midfrequency). Among the three industries, the tertiary industry contains two Kuznets cycles of 14 and 21 years, respectively. That is to say, the fluctuation of the tertiary industry was significantly affected by two different construction factors simultaneously. In addition, both primary and secondary industries include a 4.7-year political and economic cycle. That is, the fluctuations in primary and secondary industries were affected by political and economic factors like government changes. In combination with correlation coefficients and variance contribution rates, it can be seen that the Kitchin cycle always had the strongest correlation with the corresponding original sequence and the largest impact on the original sequence among the periodic components of industry fluctuations. In other words, the cyclical fluctuations of various industries in Heilongiiang Province were most affected by the inventory investment cycle.

The fluctuation components of each industry in Jilin Province include a Juglar cycle and two Kuznets cycles of 14 and 21 years, respectively. Besides, high-frequency components are slightly different. The high-frequency periodic component of primary and tertiary industries is the Kitchin cycle, while that of the secondary industry is the political economic cycle. That is, the short-term fluctuations of primary and tertiary industries in Jilin Province were mainly affected by the market while those of the secondary industry were mainly affected by political and economic factors since the implementation of the reform and opening-up policy. From correlation coefficients and variance contribution rates, it can be seen that Kitchin, political economic, and Juglar cycles had a major impact on primary, secondary, and tertiary industries, respectively. In addition, Juglar, Kuznets, and Kitchin cycles played a secondary role in primary, secondary, and tertiary industries, respectively, which indicated that high and midfrequency components exerted a great impact on original industry fluctuations. That is to say, the periodic fluctuations of various industries in Jilin Province were significantly influenced by inventory investment, political economic, and equipment investment.

The fluctuation components of each industry in Liaoning Province include Kitchin, Juglar, and Kuznets cycles. Among the three industries, the tertiary industry contains two Kuznets cycles of 14 and 21 years, respectively, the primary industry also includes the political economic cycle, and the secondary industry covers the Kondratiev cycle (low frequency) as well. From the perspective of correlation coefficients, every component was significantly correlated with the original sequence except Juglar and Kuznets cycles in the primary industry. From the perspective of variance contribution rate, high-frequency periodic components (Kitchin and political economic cycles) had the main impact on primary industry fluctuations with a total variance contribution rate of $93.36 \%$. High- and low-frequency components had a major impact on secondary industry fluctuations with the sum of variance contribution rates being $75.48 \%$. The trend term of the tertiary industry had the greatest impact on industrial fluctuations with a variance contribution rate of $40.35 \%$, while other components in total had an influence degree of $59.65 \%$, of which $50.44 \%$ came from Kitchin and Kuznets cycles, indicating that inventory investment, political economic, and construction cycles were the main factors affecting the fluctuations of various industries in Liaoning Province in addition to its own development trends.

\section{Correlation Analysis of Industrial and Business Cycle Components}

The previous section decomposed the economic and industrial fluctuation sequences of each province and 
compared and analyzed decomposition results by province. Based on the above analysis, a study was carried out on the correlation between the cyclical components of economic and industrial fluctuations. First, the table of correlation coefficients between the industrial and economic fluctuation components of each province was obtained by using MATLAB. Then, line charts were drawn using correlation information to intuitively analyze the relationship between economic and industrial fluctuation components.

Table 3 shows the correlation between the economic and industrial fluctuation components of Heilongjiang Province. It can be seen that the Kitchin cycle was significantly positively related to the Kitchin and political economic cycles of the secondary industry and especially more significantly relevant $(|r|=0.6)$ to the political economic cycle in terms of the economic fluctuation components of Heilongjiang Province. Kuznets and Kondratiev cycles were positively correlated with the Kuznets cycle of every industry and the Juglar cycle of the secondary industry $(|r|>0.5)$. To deeply study the impact of industrial fluctuation components on economic cycle components, a comparison was made between the line charts of the economic and industrial fluctuation components of each province.

Figure 3 shows some line charts of economic and industrial fluctuation components that were significantly correlated in Heilongjiang Province. Figure 3(a) shows the Kitchin cycle of economic fluctuations, and the Kitchin and political economic cycles of the secondary industry. It can be found from this graph that the Kitchin cycle of economic fluctuations was more similar to the political economic cycle of the secondary industry before the 1990s and the Kitchin cycle of the secondary industry after the 1990s, and industry fluctuations were always ahead of economic ones. The reason is that the economic system of China was officially changed from a planned economy system to a socialist market one in 1992. Government decisions played a decisive role in economic development during the implementation of the planned economy system, while the market mechanism played a major role after 1992. As seen from Table 1, the Kitchin cycle of economic fluctuations in Heilongjiang Province had a variance contribution rate as high as $51.95 \%$, which exerted a major impact on economic fluctuations. It can be seen from Table 2 that the variance contribution rates of the Kitchin and political economic cycles of the secondary industry in Heilongjiang Province accounted for more than $70 \%$ of the fluctuations of the secondary industry, indicating that the economic fluctuations in Heilongjiang Province were mainly caused by the fluctuations of the secondary industry. Furthermore, the political economic cycle was dominant before the 1990s, while the Kitchin cycle was dominant after the 1990s.

Figure 3(b) shows the line charts of the Kuznets cycles of economic and primary industry fluctuations, the Juglar and Kuznets cycles of secondary industry fluctuations and the Kuznets cycle of the tertiary industry. As seen from Figure 3 and the correlation coefficients in Table 3, the Kuznets cycle of economic fluctuations was most relevant to the Juglar cycle of the secondary industry, and industry fluctuations were ahead of economic ones, indicating that the Kuznets cycle of economic fluctuations in Heilongjiang Province was mainly caused by the Juglar cycle of the secondary industry. In addition, the Kuznets cycles of various industries had some influence on it, whose effects were the most significant in the early 21 st century. The Kuznets cycle of economic fluctuations showed a trend of steady growth at the beginning of the 21 st century due to the combined action of a significant decline in the Juglar cycle of the secondary industry and the growth of the Kuznets cycle of each industry.

The Kondratiev cycle of economic fluctuations was the same as the Kuznets cycle of economic fluctuations, which was significantly related to the Kuznets cycle of primary industry fluctuations, the Juglar and Kuznets cycle of secondary industry fluctuations as well as the Kuznets cycle of tertiary industry fluctuations. Figure 3(c) is the line chart of corresponding components. Related industrial fluctuation components were the same, but two economic fluctuation components and their relationship with industrial ones showed different trends. The average growth rate of the Kondratiev cycle of economic fluctuations was higher than that of the Kuznets cycle, and the trend of the Kondratiev cycle of economic fluctuations was more stable. In addition, it was mainly affected by the Juglar and Kuznets cycles of the secondary industry. That is to say, the Kondratiev cycle of economic fluctuations in Heilongjiang Province was mainly caused by the Juglar and Kuznets cycles of secondary industry fluctuations.

Table 4 shows the correlation between the economic and industrial fluctuation components of Jilin Province. It can be seen that the political economic cycle of economic fluctuations in Jilin Province was strongly positively related to the Kitchin cycle of primary industry fluctuations and that of the secondary industry $(|r|>0.5)$. The Juglar cycle of economic fluctuations was positively related to those of various industrial fluctuations and negatively related to the Kuznets cycle of primary industry fluctuations but only strongly correlated with those of secondary and tertiary industries $(|r|>0.5)$. The Kuznets cycle of economic fluctuations was significantly positively associated with those of the fluctuations of the three industries. Furthermore, the strongest correlation came from the Kuznets cycle of secondary industry fluctuations $(|r|>0.8)$, followed by those of tertiary and finally primary industry ones $(|r|<0.5)$.

Figure 4 shows the line charts of economic and industrial fluctuation components that were significantly correlated in Jilin Province. Figure 4(a) is the line charts of the political economic cycles of economic and secondary industry fluctuations and the Kitchin cycle of primary industry fluctuations. It can be seen that the trend of the political economic cycle of economic fluctuations was similar to that of the secondary industry in Jilin Province, and the fluctuations of industrial components were ahead of those of economic components. The trend of the political economic cycle of economic fluctuations was similar to the Kitchin cycle of the primary industry, but the amplitudes of components were quite different. That is to say, the political economic cycle of economic fluctuations in Jilin Province was mainly brought by that of the secondary industry, and the fluctuation range was affected by the Kitchin cycle of the 
TABle 3: Correlation between industrial and the economic cycle components of Heilongjiang Province.

\begin{tabular}{|c|c|c|c|c|c|}
\hline \multirow{2}{*}{ Industrial } & \multirow{2}{*}{ Industrial component } & \multicolumn{4}{|c|}{ Economic component } \\
\hline & & Kitchin cycle & Juglar cycle & Kuznets cycle & Kondratiev cycle \\
\hline \multirow{4}{*}{ Primary industry } & Kitchin cycle & 0.19 & 0.08 & 0.04 & 0.03 \\
\hline & Political economic cycle & -0.21 & 0.20 & 0.09 & 0.04 \\
\hline & Juglar cycle & -0.09 & 0.15 & 0.08 & -0.04 \\
\hline & Kuznets cycle & -0.02 & 0.02 & $0.61^{* * *}$ & $0.68^{* * *}$ \\
\hline \multirow{4}{*}{ Secondary industry } & Kitchin cycle & $0.37^{* *}$ & 0.12 & 0.01 & -0.03 \\
\hline & Political economic cycle & $0.60^{* * *}$ & $0.34^{* *}$ & 0.09 & 0.03 \\
\hline & Juglar cycle & 0.09 & 0.22 & $0.82^{* * *}$ & $0.70^{* * *}$ \\
\hline & Kuznets cycle & -0.02 & 0.06 & $0.75^{* * *}$ & $0.86^{* * *}$ \\
\hline \multirow{4}{*}{ Tertiary industry } & Kitchin cycle & 0.14 & -0.04 & 0.01 & 0.02 \\
\hline & Juglar cycle & 0.07 & $-0.40^{* * *}$ & -0.08 & 0.02 \\
\hline & Kuznets cycle & 0.05 & 0.24 & 0.03 & -0.10 \\
\hline & Kuznets cycle & -0.02 & 0.20 & $0.65^{* * *}$ & $0.31^{*}$ \\
\hline
\end{tabular}

Note. Asterisks mean that the figure is statistically significant; ${ }^{*},{ }^{* *}$, and ${ }^{* * *}$ indicate $P<0.1, P<0.05$, and $P<0.1$, respectively.

primary industry, especially before the 21 st century. The reason is that economic development mainly relied on the heavy industry as an important member of the old industrial base in Northeast China at the beginning of the reform and opening up and for a long time afterward. As a member of the main grain-producing areas in China, the primary industry also had a great impact on economic development.

Figure 4(b) shows the line charts of the Juglar cycle of economic and primary industry fluctuations and the Kuznets and Juglar cycles of secondary industry fluctuations as well as the Juglar cycle of tertiary industry fluctuations. It can be seen from Table 4 that the Juglar cycle of economic fluctuations in Jilin Province had the strongest correlation with the Juglar cycles of secondary and tertiary industries, and economic fluctuation components were weakly correlated with other industries. In addition, industrial fluctuations were ahead of economic ones. That is to say, the Juglar cycle of economic fluctuations in Jilin Province was mainly caused by those of secondary and tertiary industries and slightly attributed to that of the primary industry.

The Kuznets cycle of economic fluctuation was significantly related to those (a total of six) of primary, secondary, and tertiary industries. According to the correlation between the components of each industry and the Kuznets cycle of economic fluctuations in Table 4, it can be seen that the Kuznets cycle of the secondary industry had the greatest impact on economic fluctuations, followed by those of tertiary and finally primary industries. Figure 4(c) shows the line charts of components. It can be seen that the trends and amplitudes of Kuznets cycle of economic fluctuations were strongly consistent with the Kuznets cycle of the secondary industry while the Kuznets cycle of the tertiary industry gradually approached economic fluctuations after the 21st century, suggesting that the Kuznets cycle of economic fluctuations in Jilin Province was mainly affected by that of the secondary industry between the implementation of the reform and opening-up policy to the 21st century. The tertiary industry played an increasing role in the development of economy with the transformation of industrial structure.
Table 5 shows the correlations between economic and industrial fluctuation components in Liaoning Province. It can be seen that the political economic cycle of economic fluctuations was strongly positively related $(|r|=0.9)$ to the Kitchin cycle of the secondary industry. The Juglar cycle of economic fluctuations was significantly positively correlated with that of secondary industry fluctuations and related to the Kitchin cycles of the three industries, the 14-year Kuznets cycle of the tertiary industry, and the political economic and Juglar cycles of the primary industry. Economic and Juglar cycles were significantly related, but the coefficient was slightly lower $(|r|<0.5)$. The Kuznets cycle of economic fluctuations was significantly positively correlated with that of the three industries and the Kondratiev cycle of the secondary industry and strongly related to those of primary and secondary industries $(|r|>0.9)$.

Figure 5 shows the line charts of economic and industrial fluctuation components significantly correlated with economic ones in Liaoning Province. Figure 5(a) is a line chart of the political economic cycle of economic fluctuations and the Kitchin cycle of secondary industry fluctuations. Table 5 shows that only the Kitchin cycle of the secondary industry was significantly related to the political economic cycle of economic fluctuations among all industrial fluctuation components, and the correlation coefficient was as high as 0.9. It can be seen from line charts that the changes of industrial fluctuation components were ahead of those of economic ones, indicating that the political economic cycle of economic fluctuations was mainly caused by the secondary industry in Liaoning Province.

Table 5 shows that industrial fluctuation components related to the Juglar cycle of economic fluctuations include Kitchin and political economic cycles, the Juglar cycle of primary industry fluctuations, the Kitchin, and Juglar cycles of secondary industry fluctuations as well as the Kitchin and Kuznets cycles of tertiary industry fluctuations. To show key information clearly, Figure 5(b) only shows the political economic cycle of primary industry fluctuations, the Juglar cycle, and the Juglar cycles of economic and secondary industry fluctuations. The political economic and Juglar cycles of the primary industry were negatively related to the 


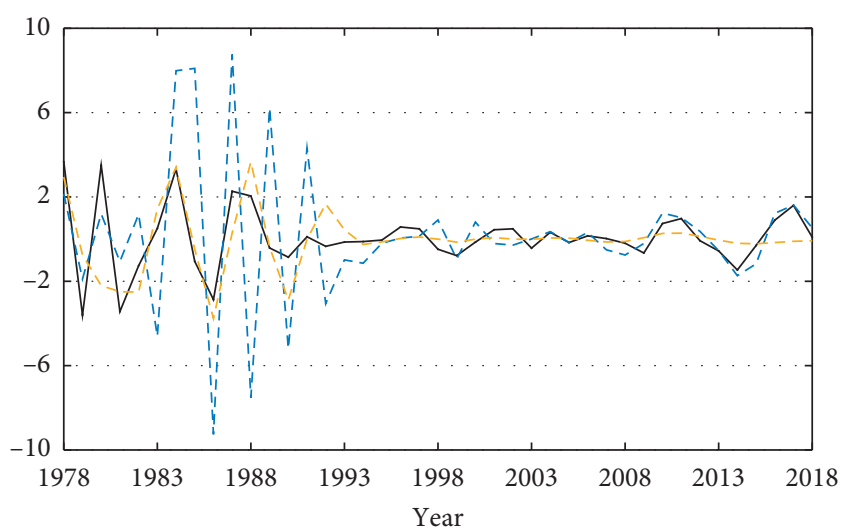

- Kitchin cycle of economy $(T=2.2)$

- - Kitchin cycle of secondary industry $(T=2.2)$

- _ Political economic cycle of secondary industry $(T=4.7)$

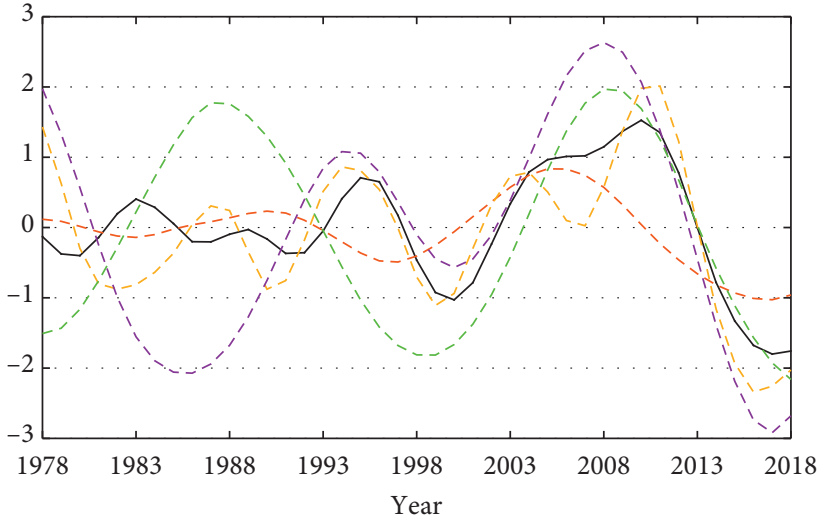

- Kuznets cycle of economy - - - Kuznets cycle of secondary $(T=21.0)$ industry $(T=14.0)$

- _- Kuznets cycle of primary _ _ - Kuznets cycle of tertiary industry $(T=21.0)$ industry $(T=21.0)$

(a)

(b)

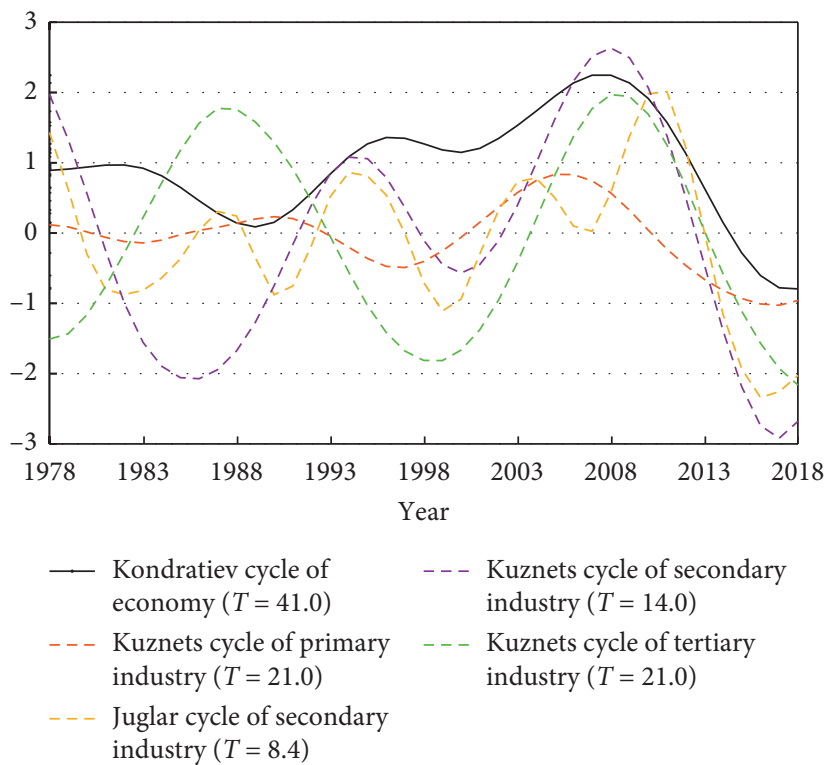

(c)

FIgURE 3: Line charts of the economic and industrial components in Heilongjiang Province. (a) Kitchin cycle of economy and related industry components. (b) Kuznets cycle of economy and related industry components. (c) Kondratiev cycle of economy and related industry components.

political economic cycle of economic fluctuations. As seen from the figure, the reason for this negative correlation is that industrial fluctuations lagged behind economic ones, indicating that economic fluctuations brought about the fluctuations of components in the primary industry of Liaoning Province and the peaks (troughs) of the industrial fluctuation cycle with the last troughs (peaks) of the economic fluctuation cycle being in the same period. However, the fluctuation trends of components were similar, but the correlation between sequences was still low due to the differences in the frequency of fluctuations between the Kitchin and Kuznets cycles of each industry and economic fluctuation components. Only the Juglar cycle of the secondary industry was strongly related to that of economic fluctuations, indicating that the Juglar cycle of economic fluctuations was mainly caused by that of the secondary industry.

Figure 5(c) is a line chart of the Kuznets cycle of economic fluctuations, the Kuznets cycles of the fluctuations of various industries, and the Kondratiev cycle of secondary industry fluctuations. As seen from the graph and Table 5, the Kuznets cycles of primary and secondary industries had the strongest connection with the Kuznets cycle of economic fluctuations, indicating that the 
TABLE 4: Correlation between industrial and the economic cycle components of Jilin Province.

\begin{tabular}{|c|c|c|c|c|}
\hline \multirow{2}{*}{ Industrial } & \multirow{2}{*}{ Industrial component } & \multicolumn{3}{|c|}{ Economic component } \\
\hline & & Political economic cycle & Juglar cycle & Kuznets cycle \\
\hline \multirow{4}{*}{ Primary industry } & Kitchin cycle & $0.64^{* * *}$ & -0.05 & -0.03 \\
\hline & Juglar cycle & -0.13 & $0.40^{* *}$ & -0.02 \\
\hline & Kuznets cycle & 0.00 & $-0.41^{* * *}$ & $0.37^{* *}$ \\
\hline & Kuznets cycle & -0.09 & -0.14 & $0.45^{* * *}$ \\
\hline \multirow{4}{*}{ Secondary industry } & Political economic cycle & $0.59^{* * *}$ & 0.20 & 0.09 \\
\hline & Juglar cycle & -0.04 & $0.75^{* * *}$ & 0.21 \\
\hline & Kuznets cycle & 0.01 & 0.08 & $0.88^{* * *}$ \\
\hline & Kuznets cycle & 0.03 & 0.05 & $0.89^{* * *}$ \\
\hline \multirow{4}{*}{ Tertiary industry } & Kitchin cycle & 0.21 & -0.05 & -0.11 \\
\hline & Juglar cycle & -0.05 & $0.83^{* * *}$ & -0.08 \\
\hline & Kuznets cycle & -0.05 & 0.01 & $0.71^{* * *}$ \\
\hline & Kuznets cycle & -0.08 & -0.15 & $0.47^{* * *}$ \\
\hline
\end{tabular}

Note. Asterisks mean that the figure is statistically significant; ${ }^{*},{ }^{* *}$, and ${ }^{* * *}$ indicate $P<0.1, P<0.05$, and $P<0.1$, respectively.

Kuznets cycle of economic fluctuations in Liaoning Province was mainly determined by that of primary and secondary industrial fluctuations. The amplitudes of the Kuznets cycle of the tertiary industry and the trend term of the Kuznets cycle of economic fluctuations were different before the 21 st century but gradually converged after the 21st century, which is because the government put forward the strategy of "Revitalizing the Old Industrial Base in the Northeast" to solve the "Northeast phenomenon" at the beginning of the 21 st century. The northeast region began to attach importance to developing the tertiary industry, especially the field of production service. Therefore, the components of tertiary industry fluctuations gradually approached the fluctuations of economic components after the 21st century.

Below is an analysis of the similarities and differences between economic and industrial fluctuations across the three provinces, each of which has three types of economic fluctuation components, namely, high-, mid-, and lowfrequency components. Firstly, the high-frequency components (short-term business cycles) of economic fluctuations in the three provinces were mainly affected by the secondary industry. The difference is that the shortterm business cycle of Heilongjiang Province was affected by the Kitchin and political economic cycles of the secondary industry simultaneously, and the short-term business cycles of Jilin and Liaoning Provinces were only affected by the political economic and Kitchin cycles of the secondary industry respectively, suggesting that the shortterm business cycle of Heilongjiang Province was affected by the combined effect of the market and government, and the market played a more obvious role from the late 1990s; the short-term business cycle of Jilin Province was mainly affected by government behavior; the short-term business cycle of Liaoning Province was mainly brought about by the factor of the market. The fluctuation ranges of shortterm business cycles in Heilongjiang, Liaoning, and Jilin provinces increased sequentially, indicating that the participation of both the market and government led to the smallest fluctuation range of short-term business cycle and contributed most to the economy.
Secondly, the midfrequency components (midterm business cycles) of economic fluctuations in the three northeastern provinces of China are all Juglar cycles. As mentioned above, the midterm business cycle of Heilongjiang Province played a negligible role in economic fluctuations, which was thus not considered here. The midterm business cycle of Jilin Province was mainly brought about by the Juglar cycles of secondary and tertiary industries, and the midterm business cycle of Liaoning Province was mainly affected by the Juglar cycle component of the secondary industry, indicating that the investment change of equipment in secondary and tertiary industries brought about the midterm business cycle in Jilin Province, the investment change of equipment in the secondary industry gave rise to the midterm business cycle in Liaoning Province, and the investment change of equipment in the primary industry had no effect on the value of output without resulting in economic fluctuations. As a matter of fact, investment in the equipment of the primary industry increased labor productivity but had no impact on the value of output.

Finally, the low-frequency components (long-term business cycles) of economic fluctuations in the three northeastern provinces of China are mainly Kuznets cycles. The same point of the three provinces is that the Kuznets cycle of the tertiary industry played an increasingly important role in their long-term business cycles after the 21st century, suggesting that the transformation of industrial structure effectively shifted economic development from "industrial dominance" to "multipoint support" and improved the stability of economic development. The difference is that the long-term business cycle of Heilongjiang Province was most affected by the Juglar and Kuznets cycles of the secondary industry, demonstrating that continuous investment in the equipment and construction of the secondary industry was the key to improving the stability of the long-term business cycle in Heilongjiang Province. The long-term business cycles of Jilin and Liaoning Provinces were mainly affected by the Kuznets cycle of the secondary industry $(T=14)$. That is to say, stable investment in the construction of secondary and tertiary industries kept the 


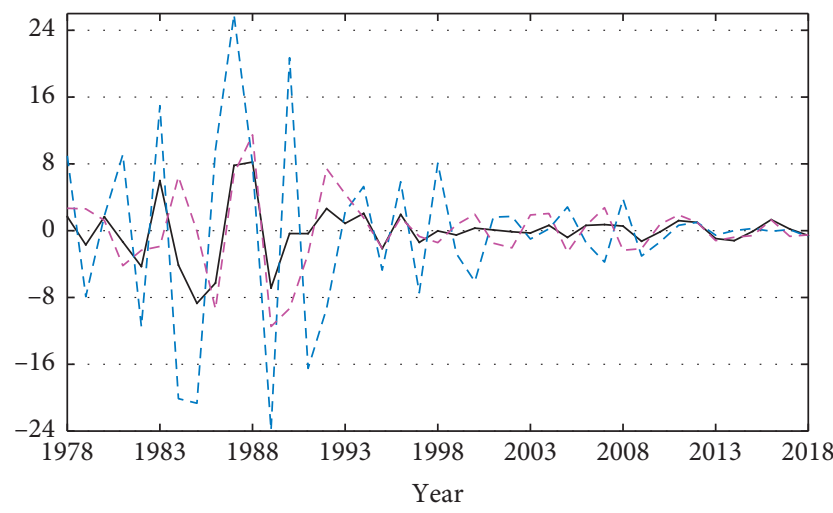

- Political economic cycle of economy $(T=4.2)$

--- Kitchin cycle of primary industry $(T=3.2)$

- - - Political economic cycle of secondary industry $(T=4.7)$

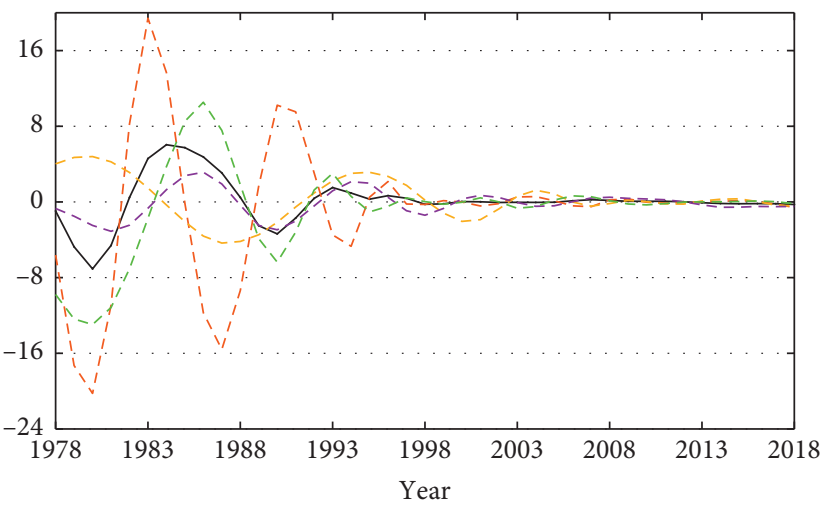
$\begin{array}{cc}\text { - Juglar cycle of economy } & --- \\ (T=10.5) & \text { Juglar cycle of secondary } \\ & \text { industry }(T=8.4)\end{array}$

- - - Juglar cycle of primary industry $(T=7.0)$ Kuznets cycle of primary industry $(T=14.0)$

(a)

(b)

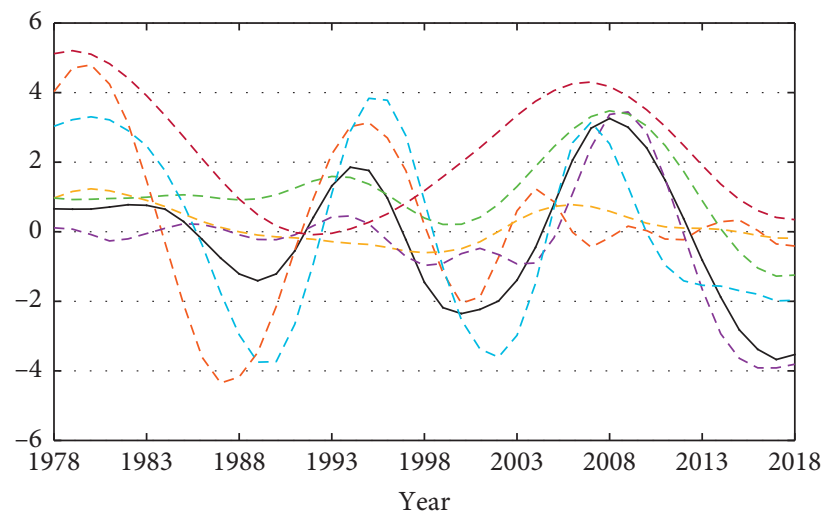

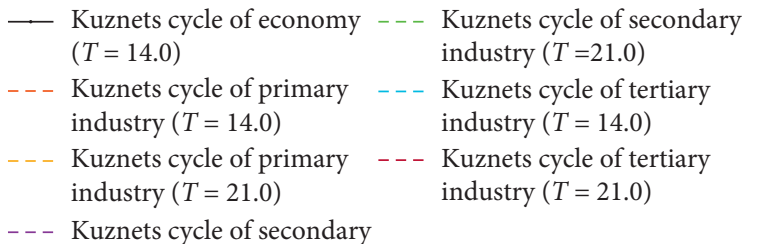

- - Kuznets cycle of secondary industry $(T=14.0)$

(c)

Figure 4: Line charts of the economic and industrial components in Jilin Province. (a) Political and economic cycle of economy and related industry components. (b) Juglar cycle of economy and related industry components. (c) Kuznets cycle of economy and related industry components.

long-term business cycle more stable in Jilin and Liaoning Provinces.

\section{Discussion}

Complex and changeable economic systems are characterized by nonstationarity and nonlinearity. As a result, researchers always deal with the data in a linear system when analyzing the economic sequence in an economic system in order to facilitate quantification and often transform nonstationary time series into stationary ones before adopting existing time series methods. The difficulty of the analysis process is reduced, but the effectiveness of analysis depends too much on the stationarity and linear assumption of data, which often leads to the loss of some information and changes the economic meaning of data. In contrast, the CEEMDAN algorithm puts forward no requirements for the stability and linearity of data, loses no information, and obtains more objective results, effectively avoiding the shortcomings of the nonlinear cointegration theory that is too complicated with weak economic significance [38].

The CEEMDAN algorithm was selected to deal with the time series of economic and industrial fluctuations since the reform and opening up, and a detailed analysis was carried 
TABle 5: Correlation between industrial and economic cycle components of Liaoning Province.

\begin{tabular}{|c|c|c|c|c|}
\hline \multirow{2}{*}{ Industrial } & \multirow{2}{*}{ Industrial component } & \multicolumn{3}{|c|}{ Economic component } \\
\hline & & Political economic cycle & Juglar cycle & Kuznets cycle \\
\hline \multirow{4}{*}{ Primary industry } & Kitchin cycle & 0.16 & $0.27^{*}$ & -0.04 \\
\hline & Political economic cycle & 0.12 & $-0.50^{* * *}$ & 0.03 \\
\hline & Juglar cycle & -0.02 & $-0.27^{*}$ & 0.14 \\
\hline & Kuznets cycle & -0.13 & 0.01 & $0.91^{* * *}$ \\
\hline \multirow{4}{*}{ Secondary industry } & Kitchin cycle & $0.90^{* * *}$ & $0.26^{*}$ & -0.07 \\
\hline & Juglar cycle & 0.13 & $0.98^{* * *}$ & 0.18 \\
\hline & Kuznets cycle & -0.08 & 0.11 & $0.96^{* * *}$ \\
\hline & Kondratiev cycle & -0.11 & 0.04 & $0.48^{* * *}$ \\
\hline \multirow{4}{*}{ Tertiary industry } & Kitchin cycle & 0.13 & $0.28^{*}$ & 0.00 \\
\hline & Juglar cycle & 0.11 & 0.12 & 0.24 \\
\hline & Kuznets cycle & 0.12 & $0.38^{* *}$ & $0.35^{* *}$ \\
\hline & Kuznets cycle & 0.01 & 0.10 & $0.59^{* * *}$ \\
\hline
\end{tabular}

Note. Asterisks mean that the figure is statistically significant; ${ }^{*},{ }^{* *}$, and ${ }^{* * *}$ indicate $P<0.1, P<0.05$, and $P<0.1$, respectively.

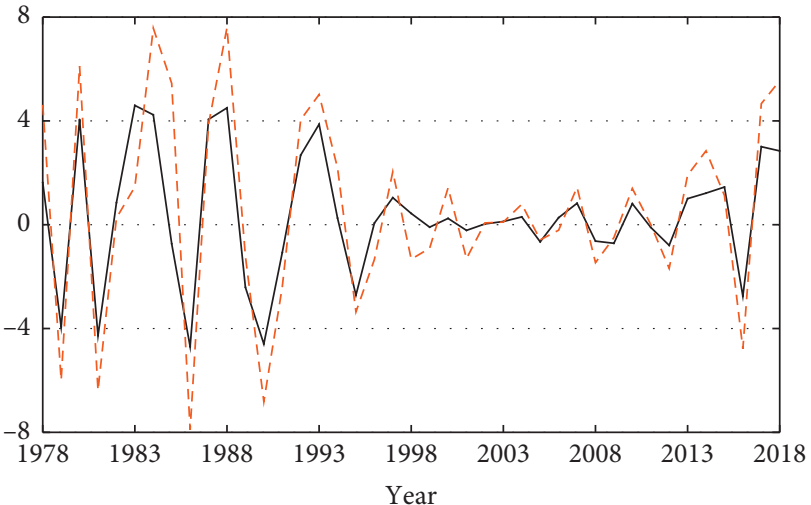

- Political economic cycle of economy $(T=5.3)$

- - Kitchin cycle of secondary industry $(T=3.8)$

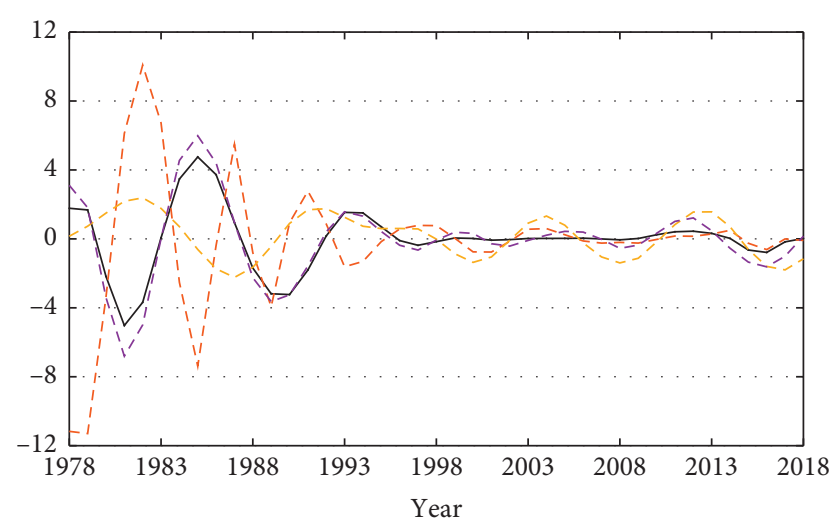

Juglar cycle of economy $(T=8.4)$

- - - Political economic cycle of primary industry $(T=5.3)$

Juglar cycle of primary industry $(T=10.5)$

- - Juglar cycle of secondary industry $(T=8.4)$

(a)

(b)

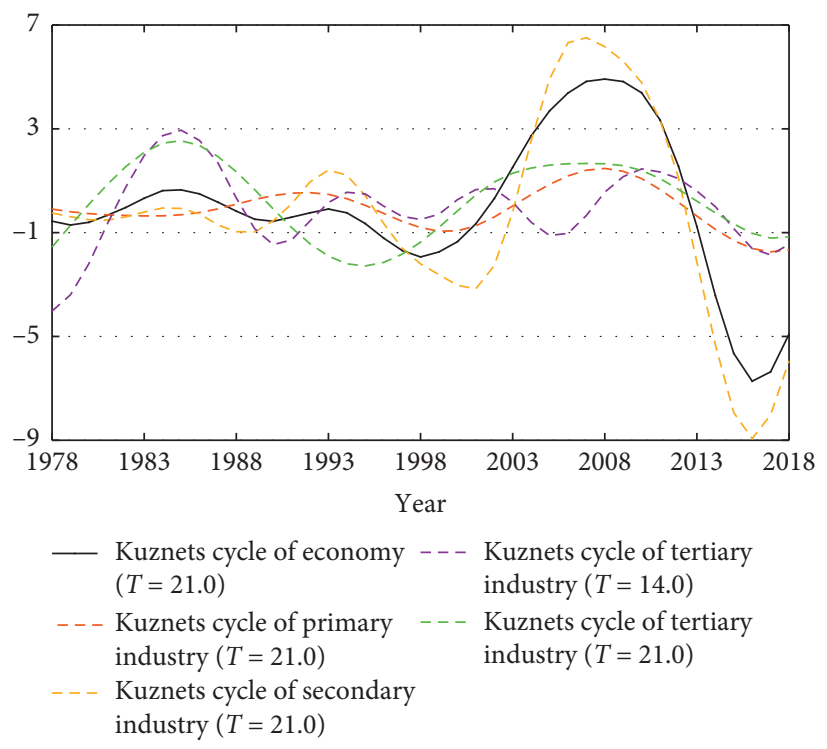

(c)

Figure 5: Line charts of economic and industrial components in Liaoning Province. (a) Political and economic cycle of economy and related industry components. (b) Juglar cycle of economy and related industry components. (c) Kuznets cycle of economy and related industry components. 
TABLE 6: Main fluctuation components of each industry in the three northeastern provinces (except trend items).

\begin{tabular}{lccc}
\hline Province & & Industry & Tertiary industry \\
\hline Heilongjiang & Primary industry & Secondary industry & Kitchin cycle \\
Jilin & Kitchin cycle & Kitchin cycle & Juglar cycle \\
Liaoning & Kitchin cycle & Political economic cycle & Kitchin cycle \\
\hline
\end{tabular}

out on the characteristics of these fluctuations in the three northeastern provinces of China. With regard to economic fluctuations, all provinces include high-, mid-, and lowfrequency components, indicating the existence of three types of cycle components, namely, short-, mid-, and longterm business cycles. Both Heilongjiang and Jilin Provinces took the short-term business cycles as the main component, which had around $50 \%$ of the impact on economic fluctuations. Economic fluctuations in Liaoning Province took a long-term business cycle as the main component, which had nearly $50 \%$ of the impact on economic fluctuations. Regarding industrial fluctuations, the med- and low-frequency components of industrial fluctuations in the three provinces are common but still show some differences. Table 6 summarizes the main fluctuation components of all industries in the three northeastern provinces of China. The main component of the primary industry is the Kitchin cycle in each province, exhibiting that the fluctuation of the primary industry was mainly affected by the investment of inventory. The main component of the secondary industry is the Kitchin cycle for Heilongjiang Province, the political economic cycle for Jilin Province, and Kitchin and Kuznets cycles for Liaoning Province, showing that the main factors for the fluctuation of the secondary industry in Heilongjiang, Jilin, and Liaoning Provinces were the inventory investment cycle and political and economic factors as well as the investment of inventory and construction, respectively. The main component of the tertiary industry is the Kitchin cycle for Heilongjiang Province, the Juglar cycle for Jilin Province, and the Kitchin cycle for Liaoning Province. However, the Kitchin cycle only brought about $20 \%$ of the impact on fluctuations more affected by the trend item in Liaoning Province, indicating that the main component of the tertiary industry was affected by inventory investment in Heilongjiang Province, equipment investment in Jilin Province, and the trend item in Liaoning Province.

It can be seen that certain differences exist in the business cycle and industrial fluctuation components of Heilongjiang, Jilin, and Liaoning Provinces. Therefore, accurate results may provide a reference for the healthy and orderly development of the regional economy. However, the research results are less precise and not specific due to the annual data and simple division of industries. Next, more specific results were obtained by starting with higher-frequency data (quarterly or monthly data) and segmented industries.

\section{Conclusion}

The components of economic and industrial fluctuations were measured by taking the three provinces of Northeast China as research areas, taking CEEMDAN as a research method, and using the time series data of GDP and industrial growth rates from 1978 to 2018. Besides, the relationship between industrial and economic fluctuations was analyzed. This paper aimed to understand economic and industrial fluctuations and their relationship so as to provide a valuable reference for the sustainable economic development of the three northeastern provinces. The main conclusions of this research are as follows:

(1) Since the implementation of the reform and opening-up policy, the economic fluctuations in the three northeastern provinces of China have almost been free from the influence of the primary industry and most affected by the development of the secondary industry. With the transformation of industrial structure, the tertiary industry gradually had an influence on economic fluctuations after the 21 st century.

(2) The short-term business cycles of the three northeastern provinces were all affected by the development of the secondary industry. To be specific, the short-term business cycle of Heilongjiang Province was affected by the combined effect of the market and government on the secondary industry, with the market playing a more obvious role after the 1990s; the short-term business cycle of Jilin Province was mainly affected by the government activities of the secondary industry; the short-term business cycle of Liaoning Province was mainly driven by the market factors of the secondary industry. And the fluctuation of the short-term business cycle was the smallest and economy was the most stable for the three northeastern provinces when the market and government participated in developing the secondary industry simultaneously.

(3) The midterm business cycles of Jilin and Liaoning Provinces are both Juglar cycles (the midterm business cycle of Heilongjiang Province played a negligible role in economic fluctuations, which was thus not considered). In addition, the midterm 
business cycle of Jilin Province was affected by the investment of equipment in secondary and tertiary industries, and that of Liaoning Province was affected by the investment of equipment in the secondary industry.

(4) The long-term business cycles of the three northeastern provinces are dominated by the Kuznets cycle. The difference is that the long-term business cycle of Heilongjiang Province was affected by the Juglar and Kuznets cycles of the secondary industry, while those of Jilin and Liaoning Provinces were mainly affected by the Kuznets cycle of the secondary industry $(T=14)$, showing that the key to maintaining the stability of long-term business cycle in Heilongjiang Province was the equipment investment of the secondary industry and the equipment and construction investment of the tertiary industry, and the key to maintaining the stability of long-term business cycles in Jilin and Liaoning Provinces was the construction investment of secondary and tertiary industries.

\section{Data Availability}

The data used to support the findings of this study are available from the corresponding author upon request.

\section{Conflicts of Interest}

All authors declare that they have no conflicts of interest.

\section{Acknowledgments}

This research was funded by Chinese National Funding of Social Sciences (16BJL032).

\section{References}

[1] B. F. Chen, "Business cycle fluctuation and industrial structure change: a literature review," Social Sciences in Hunan, vol. 6, pp. 109-113, 2010.

[2] T. W. Schultz and S. Kuznets, "Kuznets, simon, economic growth of nations; total output and production structure , cambridge, belknap press of harvard university press, 1971, XII + 363 pp. (\$15.00)," American Journal of Agricultural Economics, vol. 54, no. 1, p. 151, 1972.

[3] J. Berman and J. Pfleeger, "Which industries are sensitive to business cycles," Monthly Labor Review, vol. 120, no. 2, pp. 19-25, 1997.

[4] Y. F. Lin, F. Cai, and Z. Li, The Chinese Miracle: Development Strategy and Economic Reform, SDX Joint Publishing Company, Shanghai, China, 2002.

[5] F. Cai and Y. F. Lin, Chinese Economy, China Financial and Economic Publishing House, Beijing, China, 2003.

[6] J. T. Ma, "The mechanism of cycle fluctuation affecting structural change," The Journal of World Economy, vol. 9, pp. 88-89, 1988.

[7] J. T. Ma, "Cyclic fluctuations and structural changes - - a preliminary study on the mechanism of economic cycles affecting industrial structure," Economic Research Journal, vol. 6, pp. 65-73, 1988.
[8] J. T. Ma, "From total fluctuation to structural change - - Rediscussion on the mechanism of economic cycle affecting industrial structure change," Economic Research Journal, vol. 4, pp. 43-50, 1989.

[9] J. T. Ma, "The analysis of industrial structure change in the business cycle of China," China Industrial Economics, vol. 1, pp. 34-39, 1990.

[10] Y. E. Li, "An empirical analysis of macroeconomic fluctuation and industry construction change," Journal of Shandong University (Philosophy and Social Sciences), vol. 3, pp. 120126, 2008.

[11] B. F. Chen, "Empirical analysis on the effect of industrial structure change to economic cycle fluctuation in China," Economic Geography, vol. 30, no. 12, pp. 2030-2036, 2010.

[12] T. Sonobe and K. Otsuka, "A new decomposition approach to growth accounting: derivation of the formula and its application to prewar Japan," Japan and the World Economy, vol. 13, no. 1, pp. 1-14, 2001.

[13] M. Peneder, "Industrial structure and aggregate growth," Structural Change and Economic Dynamics, vol. 14, no. 4, pp. 427-448, 2003.

[14] S. G. Fan, X. B. Zhang, and S. Robinson, "Structural change and economic growth in China," China Economic Quarterly, vol. 4, pp. 181-198, 2002.

[15] M. Li, "Research on the correlation between industry structure and economic fluctuation," Economic Review, vol. 6, pp. 98-104, 2010.

[16] Y. Zhang and S. C. Zhang, "The effects of industrial structure upgrade on economic fluctuations in China-_ an analysis based on the three-sector new keynesian model," Journal of Business Economics, vol. 7, pp. 83-97, 2018.

[17] A. Eggers and Y. M. Ioannides, "The role of output composition in the stabilization of US output growth," Journal of Macroeconomics, vol. 28, no. 3, pp. 585-595, 2006.

[18] A. Burns, "Progress toward economic stability," American Economic Review, vol. 50, no. 3, pp. 1-19, 1960.

[19] J. G. Robert, The American Business Cycle: Continuity and Change, University of Chicago Press, Chicago, IL, USA, 1986.

[20] T. Y. Yang and Y. T. Liu, "Structural transformation and stabilization of business cycle," Economic Theory and Business Management, vol. 7, pp. 47-55, 2011.

[21] Y. Q. Lv and X. Deng, "How does isndustrial structure upgrading iron up macroeconomic fluctuation in China: DSGE model analysis on internal structure of industrial structure," Finance and Trade Research, vol. 29, no. 2, pp. 110, 2018.

[22] J. Y. Zhang and K. Zhou, "The 'stabilizers' effects of industrial structure upgrade on economic fluctuations in China: dynamic analysis based on the perspective of stick heterogeneity of departmental price," Inquiry Economic Issues, vol. 12, pp. 172-180, 2019.

[23] C. Peng, C. F. Li, and Y. S. Li, "Study on the dynamic effects of industrial structure on economic fluctuation," Industrial Economics Research, vol. 3, pp. 91-100, 2013.

[24] Z. H. Ding and M. Zhang, "Influence of industrial structure transformation on economic fluctuation of Japan: smooth or not?" World Economy Studies, vol. 1, pp. 74-79, 2013.

[25] J. Lu, Positive Research on China's Economic Cycles, China Financial and Economic Publishing House, Beijing, China, 1992.

[26] Y. J. Yuan, "Research on economic growth cycle and industrial structure change," China Industrial Economics, vol. 6, pp. 34-41, 1991. 
[27] S. Y. Zhang, "Several theoretical issues on the evolution of industrial structure in China," Research on Development, vol. 5, pp. 8-11, 1994.

[28] X. Q. Ning and B. F. Chen, "Empirical analysis on the relationship between economic cycle fluctuation and industrial structure change in China," Journal of Central University of Finance \& Economics, vol. 11, pp. 61-66, 2008.

[29] Z. C. Li, F. Chen, and W. N. Wang, "Empirical analysis on the relationship between industrial structure change and economic cycle fluctuation," Accounting and Economics Research, vol. 27, no. 1, pp. 91-96, 2013.

[30] H. Y. Zhang and J. Q. Liu, "Analysis of the correlation between industrial development and economic growth and fluctuation in China," Journal of Industrial Technological Economics, vol. 6, pp. 63-66, 2006.

[31] Q. Z. Li and P. Chen, "Empirical analysis of industrial and economic fluctuations in taiwan," Journal of Huaqiao University (Philosophy \& Social Sciences), vol. 3, pp. 65-73, 2010.

[32] P. Chen and X. H. Cao, "An empirical analysis of the economic fluctuation and industrial structure change in taiwan 1961 2008," International Economics and Trade Research, vol. 25, no. 11, pp. 59-63, 2009.

[33] Y. Y. Jiang and B. L. Jiao, "A study on the relationship between industrial structure evolution and economic growth and fluctuation of resource-based area: a case study of Shanxi province," Urban Development Studies, vol. 21, no. 2, pp. 1-5, 2014.

[34] S. M. Jiang and X. X. Zhang, "A study on economic fluctuation effect of Chinese producer services," E Ast China Economic Management, vol. 30, no. 11, pp. 109-113, 2016.

[35] N. E. Huang and S. S. P. Shen, Hilbert-huang Transform and its Applications, World Scientific Publishing Co. Pte. Ltd., London, UK, 2014

[36] N. E. Huang, Z. Shen, S. R. Long et al., "The empirical mode decomposition and the hilbert spectrum for nonlinear and non-stationary time series analysis," Proceedings Mathematical Physical and Engineering Ences, vol. 454, no. 1971, pp. 903-995, 1998.

[37] T. M. Gao, L. Chen, J. M. Wang et al., Business Cycle Fluctuation Analysis and Forecasting Method, Tsinghua University Press, Beijing, China, 2015.

[38] X. X. He and T. Sun, "The development of empirical mode analysis and its application in economic analysis," Economic Perspectives, vol. 7, pp. 32-37, 2014. 